\title{
Teachers working in culturally diverse classrooms: implications for the development of professional standards and for teacher education.
}

\begin{abstract}
This paper reports the outcomes of a survey to investigate the level of cultural understanding and confidence for teachers working in culturally diverse classrooms. The survey was administered to teachers in primary and secondary schools in an Australian regional city. The aim of analysis was to determine the direction and strength of association of six demographic variables with measures of cultural awareness among teachers and confidence in supporting the learning of students. It found that teacher responses to working in culturally diverse classrooms varied according to levels of familiarity with the cultural groups concerned and with the level of schooling within which the teacher worked. The paper outlines the implications of these findings for the development of professional standards and for teacher education. It discusses how these findings contribute to further investigations into the extent to which teachers understand cultural diversity and their confidence as literacy instructors.
\end{abstract}

Keywords: cultural diversity; teachers; standards; teacher education

\section{Introduction}

New times are characterised by the processes of globalisation, which include, among other elements, the travel of people on a scale not previously experienced (Appadurai, 1996; Marginson, 1999; Rizvi, 2000; Smelser, 2003). Such global travel has resulted in increasingly diverse cultures and cultural diversity has become a feature of all institutions in a globalised society, including education. In Australia, this increasing travel has increased the diversity of student populations in classrooms (House of Representatives Standing Committee on Education and Vocational Education, 2007; Thomas \& Cooper, 2005). While schools are culturally, socially, and linguistically diverse (Causey, Thomas \& Armento, 2000), populations of pre-service teachers are characteristically white, middle-class, and monolingual (House of Representatives Standing Committee on Education and Vocational Education, 2007). As a consequence, pre-service teachers are likely to become teachers of children whose cultural background and life experiences are very different from their own. 
This situation provides a challenge for teachers in two ways. First, teachers are challenged to promote student understandings of cultural diversity, as highlighted by one of the national goals for education that expects that "all students in schools understand and acknowledge the value of cultural diversity and possess the knowledge, skills, and understanding to contribute to and benefit from such diversity” (MCEETYA, 1999, pp.3-4). Second, teachers are challenged also to design and implement learning experiences that enable children from all cultural groups to achieve academically (Education Queensland, 2003; Queensland College of Teachers, 2007). It is this second challenge that has prompted the research outlined in this paper.

Several studies (Banks, 2004; Larke, 1990; Nieto, 2004; Sleeter \& Grant, 2003; Yeung, 2006) have recognised that a student's academic achievement is influenced by the teacher's cultural awareness. Indeed, Brown (2004) noted the strong correlation between teacher awareness of cultural diversity and the teaching methods used. That is, teachers exhibiting high levels of cultural sensitivity prove to be effective in culturally diverse settings (Cruikshank, 1986; Larke, 1990). Therefore, for students to achieve academically, it is important that teachers have high levels of cultural understanding and feel confident working in culturally diverse classrooms. This paper presents the results of a survey into teachers' levels of cultural understanding and their support of the academic literacy needs of students from one particular cultural group. The paper first describes the study, the participants and the survey. After summarising the initial findings of the survey, the paper identifies demographic variables that predict high levels of cultural awareness among teachers, and confident teacher responses to the challenges presented by diverse school populations. The paper concludes with a discussion of the implications of these findings both for the development of professional standards and for teacher education.

\section{Investigating teacher understandings of cultural diversity}


The study was situated in a culturally diverse city in South-East Queensland, a city where more than 160 different cultural backgrounds are represented (Australian Bureau of Statistics, 2003). Approximately $30 \%$ of the population in the central district of the city was born overseas, with $22 \%$ speaking a language other than English. The largest non-Englishspeaking background (NESB) group in the city is from the Pacific Islands. Other significant language groups include speakers of Chinese, Spanish, Khmer and Tagalog/Filipino. In recent years, there has been a significant increase in the number of migrants admitted to Australia with refugee status (House of Representatives, Commonwealth of Australia, 2004). Thus, for teachers in this city, global population shifts have resulted in local school communities with a rich mix of cultural and linguistic diversity.

Teachers working in this regional city were surveyed about their levels of cultural understanding and their support of the literacy needs of students with a Pacific Islander (PI) heritage, that is, students whose families originated from Samoa, Tonga, Niue, Fiji, Tokelau, Tuvalu or the Cook Islands. This group of students was selected for two reasons. First, they represent the largest and one of the fastest-growing, ethnic groups in the South-East region of Queensland (Australian Bureau of Statistics, 2003). Second, and more importantly, the survey was prompted by anecdotal evidence, gathered during other research studies in the area (cf. Kearney, Dobrenov-Major and Birch, 2005), that teachers were concerned about the educational underachievement particularly of PI students in local schools and in the area of literacy.

It is difficult to specify the extent of underachievement for this cohort of students as performance data achieved though annual state wide tests in Queensland are not disaggregated so as to identify the achievement of particular cultural groups other than Aboriginal and Torres Strait Islander (ATSI) students. Consequently, the specific patterns of achievement among cultural groups such as PI students are not available. State data are 
provided for students with a language background other than English (LBOTE), a cohort whose performance on literacy tests is reported as similar to that of students with an Englishspeaking background (The State of Queensland, Office of the Queensland Studies Authority, 2004). However, these data are also not disaggregated beyond ATSI students. It is possible that the underachievement of PI students within the LBOTE group is masked by the performance of LBOTE students who have well-developed English literacies. This proposal is supported by Singh's (2001) report that, in 1997, when performance data achieved through state-wide testing of Year 6 students in Queensland schools were disaggregated to show the performance of cultural groups, the literacy performance of Samoan students, being the largest PI group, was “extremely below the performance of the whole cohort of students” (p. 322).

International studies conducted in other diasporic PI communities in the United States (Janes, 2002) or in New Zealand (McCaffery \& Tuafuti, 2003; McNaughton, Phillips, \& MacDonald, 2003) also suggest trends of underachievement. In addition, the Programme for International Student Assessment (PISA) data ${ }^{1}$ for New Zealand (Ministry of Education, New Zealand, 2004) showed that Pasifika² students' literacy achievement, on average, was significantly lower than the mean scores of Pakeha ${ }^{3}$, Asian and Maori students, with only 25\% of Pasifika students performing above the mean score for non-Pasifika students. This suggests significant skewing towards underachievement. Thus, the students of PI heritage presented as a particular cultural group with consistently low levels of academic achievement. The concerns of the teachers mentioned above confirmed that there was a need to investigate teachers' ability and confidence in meeting the literacy needs of PI students, and, in the light of research linking academic achievement to cultural sensitivity noted above, to link this investigation to teachers' cultural awareness and intercultural understanding. Therefore, data from the survey were analysed in order to determine the association of a set 
of teacher demographic variables with levels of intercultural understanding of the teachers, and with their levels of confidence in supporting the literacy needs of PI students.

\section{The Participants}

Three hundred and four teachers responded to the survey. They represented eleven schools located in the central and south western districts of the city. Ten of the schools were government schools. Seven of these were primary schools; three were secondary schools. Teachers from one non-government school were also involved. This school catered for students in preschool, primary and secondary levels of schooling. More than $50 \%$ of respondents had been teaching for more than eight years. In total, $67 \%$ of teachers who responded to the survey were secondary teachers. Almost $20 \%$ identified as bilingual or multilingual. Of this group, 68\% spoke European languages, 17\% spoke Asian languages, 12\% spoke Indian languages, while 3\% spoke a South-Pacific language, specifically, Cook Island Maori. Approximately $72 \%$ of teacher respondents claimed that at least $10 \%$ of their students had a non-English-speaking background (NESB). Almost 25\% of teachers indicated that at least a third of students in their classes were NESB. Most teachers reported limited training to work in classrooms that included NESB students, for example, $19 \%$ agreed that their pre-service training provided opportunities to develop as a teacher of NESB students; 35\% identified in-service opportunities that had benefited their teaching in this area; while $16 \%$ had opportunities as part of postgraduate study.

Each of the schools had significant populations of students speaking a PI language at home, with $26 \%$ of teachers agreeing that this cultural group was represented in their classrooms. Reports of other cultural groups are reported in Figure 1. While the teachers in secondary schools were more likely to teach students from European and Middle-Eastern cultures, the teachers in primary schools reported students from African and Asian cultures. This trend reflects the increasing trend for refugee families from Africa and Asia to re-settle 
in regional areas, and is consistent with current policy of the State government on immigration, which suggests that "the interests of Queensland will be best served by strategies which encourage migrants to settle in regional areas which can offer employment or business opportunities, with a view to stimulating regional economies” (Multicultural Affairs Queensland - Department of the Premier and Cabinet,1999, p. 5). As noted in Figure 1, the linguistic background of teachers differed from those of their students. Most teachers reporting bilinguility or multilinguality had a European heritage. In contrast, students represented a range of cultural heritages with PI heritage being reported most frequently.

[Insert Figure 1 here]

The survey

The self-report survey consisted of three parts. The first part consisted of a set of demographic items where respondents were asked to identify: years of teaching experience; current teaching sector, i.e. primary or secondary school; experience working with NESB children; and their own linguistic status, i.e. monolinguality, bilinguality, multilinguality. Those who were bilingual or multilingual were asked to nominate languages spoken. In addition, respondents were asked to indicate training opportunities, involving pre-service, inservice or post-graduate study, which might have prepared them for work with NESB students. These data enabled description of the sample of teachers who responded to the survey, and investigation of the relationship between a set of demographic variables and two dependent variables: intercultural understanding, and support of PI students' literacy development. In the second part of the survey, respondents were provided with a set of seven statements and asked to respond to each of these using a five-point Likert scale. Six of these items were constructed to measure the two dependent variables. A seventh item indicated the teachers’ level of happiness with their PI students' general academic achievement. The third part of the survey required respondents to provide responses to open questions that provided 
qualitative data in regard to the seventh item. This paper reports on data associated with the first and second parts of the paper with the purpose of identifying demographic variables that associate with teachers' intercultural understanding and levels of confident support for PI students’ literacy development. See Appendix for a copy of the survey.

\section{Analytic procedure}

Data analysis involved three phases. First, descriptive statistics were generated to determine teachers' levels of intercultural understanding and their confidence in supporting the literacy development of PI students. Second, data were entered into a confirmatory factor analysis to test the ability of the predefined model to fit the survey data. Third, a set of multivariate tests was conducted to determine the direction and strength of relationship between dependent and independent variables.

\section{Teacher responses to culturally diverse classrooms}

The analysis of teachers' responses to the survey focused on two areas, their confidence in providing support for the literacy development of students and on measuring levels of intercultural understanding. The following discussion outlines the findings in each area and gives further details about the analytic procedures.

\section{Providing support for literacy development}

Responses to Likert-scale items, as reported in Figure 2, indicated that approximately half of the respondents agreed or strongly agreed that they could determine the language proficiency of their Pacific Island students, with slightly higher levels of confidence in relation to speaking and listening than reading and writing. However, only $38 \%$ of teachers agreed or strongly agreed that they were confident in responding to those needs. These three 
items were used together to measure teachers' confidence in identifying and responding to the literacy development of students with a PI heritage.

[Insert Figure 2 here]

\section{Measuring intercultural understanding}

Responses to items that allowed a measure of teachers' intercultural understanding are provided in Figure 3. About one-quarter of teachers agreed or strongly agreed that they were aware of traditional communication patterns within PI cultures and knew how PI languages differed from English. A further 38\% claimed familiarity with social and cultural expectations associated with PI cultures.

[Insert Figure 3 here]

Modelling academic achievement and cultural proficiency as latent variables

As shown in Figure 4, the confirmatory factor analysis comprised two latent variables with three items representing each variable. In addition, a single item signified teachers' selfreported levels of happiness with the academic achievement of their PI students.

[Insert Figure 4 here]

Estimates of fit for the model illustrated in Figure 4 were within the threshold for acceptable fit. Examples include the chi square/degrees of freedom ratio (Chi/Df) $=2.354$; the Bentler comparative fit index $(\mathrm{CFI})=0.977$; the Tucker-Lewis Index $(\mathrm{TLI})=0.959$; and the Goodness-of-fit index (GFI) $=0.973$.

Examining associations between scale scores and demographic variables

A series of multivariate ANOVAs were conducted with six demographic variables as independent variables, and with intercultural understanding and teaching confidence as dependent variables. The six independent variables included: years of teaching experience, 
teaching sector, training opportunities, linguistic status, cultural groups taught, and percentage of NESB students in classrooms. Significant associations were examined further by non-parametric testing (Kruskal-Wallis). Findings revealed nonsignificant associations between the scale scores for intercultural understanding and four of the six independent variables, including: Years of teaching experience, type of training; experience working with different cultural groups; and numbers of NESB students being taught. However, the interaction between teaching sector and teachers' linguistic status was significant Roy’s largest root=0.039, $\mathrm{F}(6,526)=3.413, \mathrm{p}<0.05)$.

[Insert Figure 5 here]

[Insert Figure 6 here]

As shown in Figures 5 and 6, univariate testing indicated this interaction to be significant $(F(3,263)=3.34, p<05)$ such that monolingual teachers of students in Years 4 and 5 appeared to respond more positively than those in the early years of primary schooling or in secondary school. In contrast, the differences appeared to be less pronounced for multilingual teachers.

This interaction was examined further by splitting the dataset by linguistic status and performing MANOVAs for monolingual and multilingual teachers separately. As expected, the multivariate effect for Teaching status was significant for monolingual but not for multilingual teachers. The effect of teaching area for monolingual teachers was particularly pronounced in relation to being able to determine the proficiency of PI students as readers and writers. Teachers of students in Years 6 and 7 were significantly less likely ( $\left.\chi^{2}=10.229(3), p<0.05\right)$ than others, especially those working in the first five years of schooling, to respond positively to the proposal that they were able to determine the English language proficiency of PI students as readers and writers. 
A separate MANOVA was used to examine the association between training opportunity (Preservice, Inservice, PostGrad) as IV, and Academic and Cultural confidence as DVs, the interaction between training opportunities at post-graduate and pre-service levels was significant (Roy's Largest Root $=0.03, \mathrm{~F}(2,277)=3.91, \mathrm{p}<0.05)$. Univariate testing found the effect to be significant for teacher confidence $(\mathrm{F}(1,278)=7.29, \mathrm{p}<0.01)$. Follow-up testing indicated that teachers with any type of training opportunity: pre-service, in-service, or postgraduate training were more confident than those without that training on all three items representing the factor associated with teachers' confidence. In addition, those with postgraduate training only were more confident than those with either pre-service or inservice training only.

The percentage of NESB students taught by a teacher influenced scores at the multivariate level (Roy's Largest Root $=0.03, \mathrm{~F}(2,224)=3.26, \mathrm{p}<0.05)$. The interaction of the percentage of NESB students taught with the teaching of different cultural groups also influenced scores at the multivariate level (Roy’s Largest Root $=0.06, \mathrm{~F}(19,225)=2.83, \mathrm{p}<0.05$ )

Univariate testing indicated the effect for Percentage of NESB students $(\mathrm{F}(1,225)=6.52, \mathrm{p}<0.05)$ and also the interaction between Percentage of NESB students and cultural group $(\mathrm{F}(5,225)=2.83, \mathrm{p}<0.05)$ to be statistically significant. Examination of mean estimates indicated that students with more than $20 \%$ of NESB students in their classroom were more positive in terms of responses on the scale. The interaction between percentage of NESB students and teaching of cultural groups is illustrated in the error plot provided in Figure 5. This figure indicates that teachers of Indigenous students were more confident than those with fewer such students.

Follow-up nonparametric Kruskal-Wallis tests were used to examine associations between percentage of NESB for each of the three items on the teaching confidence scale, and for each of the six cultural groups. These tests found that teachers with more than $20 \%$ of NESB 
students in their classroom where Indigenous students were included were significantly more likely to report confidence in determining PI students’ proficiency as speakers and listeners $\left(\chi^{2}(1)=4.71, \mathrm{p}<0.05\right)$, and in responding to PI students' English literacy needs $\left(\chi^{2}(1)=6.18, \mathrm{p}<0.05\right)$. In addition, teachers with more than $20 \%$ of NESB students, where European students were included, were significantly more likely $(\mathrm{p}<0.05)$ to report proficiency in responding to PI students as readers and listeners $\left(\chi^{2}(1)=5.44, \mathrm{p}<0.05\right)$ plus confidence in responding to literacy needs $\left(\chi^{2}(1)=6.18, \mathrm{p}<0.05\right)$.

\section{Discussion}

The findings outlined above identified variables that impact on these teachers' understandings of cultural diversity and their confidence in supporting students' from diverse cultural backgrounds. A closer study of these findings points to the need to consider five key areas when seeking to address the issue of teachers' understandings of cultural diversity. The following discussion examines each area, identifying implications for teacher education, for the development of professional standards for teachers and for future investigations into teachers’ cultural understandings of cultural diversity.

First, the findings relating to teachers' confidence in dealing with different cultural groups point to the importance of familiarity. That is, teachers reported to feel most comfortable with students from ATSIC or European backgrounds, cultural groups with which they were most familiar. Whilst the survey findings themselves do not provide an explanation of this phenomenon, they do point to the need for further investigations. Such investigations could be framed around theories of otherness. Kristeva (1991) has described the sense of astonishment that revolves around a confrontation with the unknown. She notes that each time an unknown experience is confronted, there is a questioning of both the self and the other. The teachers in this study appeared to be questioning their professional abilities when 
working with students from unknown cultural backgrounds. Future investigations, therefore, into intercultural understandings could examine teachers' constructions of the self as professional and of their students as the other. Questions of otherness have implications also for teacher education, which will be discussed further below.

Second, the different responses from teachers in different teaching areas need further examination. In each analysis, teachers in the primary sector were more positive about their understandings of cultural diversity and about their ability to meet the students' needs. These findings support moves in Queensland to realign curriculum, pedagogy and assessment in the middle phases of schooling (Haines \& Thomas, 2005) through the introduction of more flexible, integrated curricula for early adolescents. Such curricula would be characterised by a focus on the identified needs, interests and concerns of students; an emphasis on selfdirected, co-constructed learning; taking account of local needs and circumstances and be being community-oriented, involving productive partnerships with parents and community organisations (Barratt, 1998; Chadbourne, 2001; Carrington, 2004). Thus both the survey results and the ongoing curriculum reform have implications for teacher education in primary, middle school and secondary programs.

Third, the survey results reinforce the need for understandings of cultural diversity to feature in any framework of professional standards for teachers. Currently, in Australia, there is a move towards the development of a national set of professional standards. At the same time, Queensland has developed Professional Standards for teachers working in the state, or public, education system (Education Queensland, 2003). Of the twelve standards listed, only one explicitly refers to students' cultures. This reference is found in the second statement for standard 10: Build relationships with the wider community, which noted that teachers should “establish learning environments that acknowledge the concerns, values and priorities of students’ families, cultures and communities” (Education Queensland, 2003, p. 7). Standard 
10 is linked to, and reinforces, statement 4.3, "Provide learning experiences that establish connections with the world beyond the classroom” (Education Queensland, 2003, p.6). The fifth standard is also concerned with the construction of learning experiences and statement 5.2, "Design and implement learning experiences that are inclusive and that recognize and celebrate difference” (Education Queensland, 2003, p.6), is particularly significant to understandings of cultural diversity and otherness. It should be noted that these standards emphasize the construction of learning environments, an area in which the teachers who responded to the survey did not feel confident.

More recently, the Queensland College of Teachers (QTC), a statutory body with responsibility for the registration of teachers, has developed a set of professional standards for teachers in all Queensland schools. Standard 4: Design and implement learning experiences that value diversity (Queensland College of Teachers, 2007, p. 10), is particularly pertinent to teachers' understandings of culturally diversity. Unlike the Education Queensland standards discussed above, this standard is described in terms of the practices expected of teachers, the knowledge that teachers possess and renew, and the key professional values for this aspect of practice. In terms of practice, teachers are expected to demonstrate this standard by applying professional knowledge and understanding of learners, the curriculum, teaching and learning to (among other things):

- Develop understandings about the diverse characteristics and backgrounds of the students they teach, including their families, communities, culture, home language, skills, interests, learning strengths and weaknesses, individual learning needs and prior learning and achievements [emphasis added] (Queensland College of Teachers, 2007, p. 10). 
The professional standards identified several areas of knowledge that would support teachers in to implement this practice. Teachers should know and understand:

- Factors such as socio-economic circumstances, location, gender, sexuality, ethnicity, culture, language, religious beliefs and individual needs and their impact on the world of students ...

- Supports for and barriers to responding to diversity in school environments

- The negative impact of bias, prejudice and discrimination on students, families and communities

- Cross-cultural sensitivities and perspectives [emphasis added] (Queensland College of Teachers, 2007, p. 10).

Thus, knowledge of, and sensitivity to, cultural diversity is now an essential component of a professional standard that require teachers to value and respond to diversity. That is, teachers need to develop the very knowledges, skills, sensitivities and confidence to work with culturally diverse students, families and communities that the participants in this study reported that they lacked. The introduction of this professional standard has implications for the teacher education programs that prepare students to meet these requirements, which points to the fourth challenge arising from the survey.

Fourth, the survey results present challenges to teacher education. Challenges stem from preparing graduates to meet the professional standards developed by Education Queensland and the Queensland College of Teachers. Indeed, in Queensland, teacher education programs are accredited by the QCT, which is also responsible for advising the Minister on the standards of courses for teacher education acceptable for the purposes of teacher registration. As such, all pre-service teacher education programs in Queensland need to demonstrate that graduates from these programs meet these standards. More importantly, given the importance 
of teachers' cultural awareness when working in culturally diverse classrooms, challenges arise when attempting to address the questions of otherness discussed above.

Other studies, internationally and nationally, have been critical also of teacher educators’ level of success in preparing teachers for working in culturally diverse classrooms. For example, according to Leeman and Ledoux (2003), European teacher educators have adopted a narrow and superficial approach to intercultural education, failing to achieve a critical perspective. Similarly, American research suggests that teacher education programs have done little to prepare teachers to work with culturally and linguistically diverse children (Arias \& Poynor, 2001; Jenks, Lee \& Kanpol, 2001). Studies of pre-service teachers’ cultural awareness have found that pre-service teachers in both Northern America (Larke, 1990) and Hong Kong (Yeung, 2006) reported feelings of discomfort when working with students from culturally diverse backgrounds. Both groups shared stereotypical assumptions regarding cultural diversity and academic achievement. Further, Yeung (2006) notes the little work has focused on the preparation of teachers to work in culturally diverse settings.

More positively, other studies do report on initiatives that work towards this end. Such initiatives include: ensuring the population of both teacher education students and teacher educators reflects the cultural diversity found in the wider population (Causey, 2000; Chen, 1997; House of Representatives Standing Committee on Education and Vocational Education, 2007); introducing an explicit focus on the cultural identity of students and teacher educators (Allen \& Hermann-Wilmarth, 2004; Cockrell, Placier, Cockrell \& Middleton, 1998; Hoban, 2004); and changing practices in courses that address issues of diversity. Suggestions for the latter can be found in action research projects (Cockrell et al., 1998), peer mentoring (Devereaux, 2004), and cultural portfolios (Lea, 2004). Teacher education programs need to explore the possibility of including such initiatives in their courses. 
Significantly, there was other positive news from the findings for teacher education in that the teachers with any type of pre-service, in-service, or postgraduate studies in cultural diversity were more confident in supporting NESB students' literacy needs. This finding supports the inclusion of innovative courses, such as those noted above, in teacher education programs. Further, the finding that the most confident teachers had postgraduate study emphasises the need to develop more postgraduate programs in this area. Such programs could be linked to professional development programs that are conducted in partnership with culturally diverse communities.

Finally, the survey results have implications for the research design of future studies. Whilst the findings identify variables that impact on teachers' intercultural understandings and on their confidence to deal with cultural diversity, their contribution to deeper or more fine-grained insights into teachers' understandings of cultural diversity is limited. The findings do not offer a detailed explanation of why teachers responded in the ways in which they did. Nor do they offer an explanation for the impact of the variables. For example, the survey identified the number of NESB students in a class as having a significant effect on teachers' confidence in responding to students' needs. While it did not give an explanation for this effect, class size has long been acknowledged as a crucial predictor of teacher effectiveness.

For these reasons, the survey results highlight both the weaknesses inherent in purely quantitative or broad brush studies and the need for supplementing the future surveys with data gathered through qualitative means. That is, future investigations into teachers' intercultural understandings should heed Chatterji's (2005) call for "the formal study of contextual and site specific variables with multiple research methods”. Endorsing any single research method to the exclusion of others ignores "critical realities about social, organizational, and policy environments in which education programs and interventions 
reside” (p. 14). Mixed method approaches to research design seek complementarity by combining methods to obtain a more rounded picture of a construct (Green \& Caracelli, 1997) such as sensitivity to culturally diversity. For these reasons, the findings highlight the need for mixed method research in future investigations if the fuller complexity of the issue is to be understood.

\section{Conclusion}

This paper has reported on the findings of a survey of teachers' understanding of cultural diversity in an Australian regional context. An analysis of the impact of six variables on teachers' intercultural understandings and on their confidence in working in culturally diverse classrooms revealed four areas that held implications for the development of professional standards, for teacher education and for further investigations into teachers' understandings of cultural diversity. The discussion of these areas highlighted both the complexity of this issue and the need for a multi-faceted approach to both the development of, and future investigations into, teachers' understandings of culturally diverse classrooms. 


\section{Notes}

1. The Programme for International Student Assessment (PISA), commissioned by the Organisation for Economic Co-operation and Development (OECD), is an international study that assesses the skill and knowledge of 15-year-old students in reading literacy, mathematical literacy, and scientific literacy.

2. In New Zealand, "Pasifika” refers to a person of Pacific Islander descent. In this paper, the term "Pacific Islander” has been used as its usage is common in South-East Queensland.

3. In New Zealand, “Pakeha” refers to a person of European descent. 


\section{References}

Allen, J. B., \& Hermann-Wilmarth, J. (2004). Cultural construction zones. Journal of Teacher Education, 55(3), 214-226.

Australian Bureau of Statistics. (2003). 2001 Census Basic Community Profile: Central District, Logan City. Canberra: Commonwealth of Australia.

Banks, J. A. (2004). Multicultural Education - Historical Development, Dimensions, and Practices. In J. A. Banks \& C. A. M. Banks (Eds.), Multicultural Education - Historical Development, Dimensions, and Practices (pp. 3-24). San Fransisco, California: JoseyBass.

Barnard, R. (2003). Introduction. In R. Barnard, \& T. Glynn, T. (Eds.). Bilingual children’s language and literacy development. Clevedon, England: Multilingual Matters Ltd.

Barratt, Robyn (1998a). Shaping Middle Schooling in Australia: A Report of the National Middle Schooling Project. ACT: Australian Curriculum Studies Association.

Brown, E. L. (2004). What Precipitates Change in Cultural Diversity Awareness During a Multicultural Course: The Message or the Method? Journal of Teacher Education, 55(4), 325-340.

Carrington, Victoria (2004). Mid-term Review: The Middle Years of Schooling. Curriculum Perspectives, 24(1), 30-41.

Causey, V. E., Thomas, C. D., \& Armento, B. J. (2000). Cultural diversity is basically a foreign term to me: The challenges of diversity to preservice teacher education. Teaching and Teacher Education, 16, 33-45.

Chadbourne, Rod (2001). Middle Schooling for the Middle Years: What might the jury be considering? South Bank, Victoria: Australian Education Union. 
Chatterji, M. (2005). Evidence On "What Works": An Argument For Extended MixedMethod (ETMM) Evaluation Designs. Educational Researcher, 34(5), 14-24.

Chen, G-M. (1997, January 1997). A review of the concept of intercultural sensitivity. Paper presented at the Biennial Conference of the Pacific and Asian Communication Association, Honolulu, Hawaii.

Cockrell, K. S., Placier, P. L., Cockrell, D. H., \& Middleton, J. N. (1998). Coming to terms with "diversity" and "multiculturalism" in teacher education: Learning about our students, changing our practice. Teaching and Teacher Education, 15, 351-366.

Cruikshank, D. (1986). Profile of an Effective Teacher. Educational Horizon, 64(2), 80-86.

Devereaux, L. (2004). When harry met sarita: Using a peer-mentoring program to develop intercultural wisdom in students. Paper presented at the HERDSA Conference 2004, University of Canberra.

Education Queensland. (2003). Professional standards for teachers: Guidelines for professional practice: Retrieved August 7, 2003, from http://education.qld.gov.au/staff/learning/standards/teachers/pdfs/profstandards.pdf.

Greene, J. C., \& Caracelli, V. J. (1997) (Eds). Advances in mixed-method evaluation: The challenges and benefits of integrating diverse paradigms. New Directions in Education, 74. San Francisco, CA: Jossey Bass Publishers.

Haines, S. S., \& Thomas, S. (2005, May 30 - June 1). The 'new basics' in a traditional high school- teacher experiences in aligning curriculum, pedagogy and assessment. Paper presented at the Redesigning Pedagogy: Research, Policy, Practice Conference, Singapore.

Hoban, G. F. (2004). Seeking quality in teacher education: A four-dimensional approach. Australian Journal of Teacher Education, 48(2), 117-133. 
House of Representatives Standing Committee on Education and Vocational Education (2007) Top of the Class Report on the inquiry into teacher education. Canberra: Commonwealth of Australia.

Janes, C.R. (2002). From village to city: Samoan migration to California. In P. Spockard, J.L. Rondilla, \& D. Hippolite Wright (Eds.). Pacific diaspora (pp. 118-132). Honolulu, HI: University of Hawai’i Press.

Kearney, J., Dobrenov-Major, M., Birch, G. (2005, July). Local responses to the needs of Samoan students: Implications for preservice education programs. Paper presented at the Australian Teacher Education Association $33^{\text {rd }}$ Annual Conference Gold Coast, Queensland, Australia.

Kristeva, J. (1991). Strangers to Ourselves. London, Harvetser.

Larke, P. J. (1990). Cultural Diversity Awareness Inventory: Assessing the Sensitivity of Preservice Teachers. Action in Teacher Education, 3, 23-30.

Lea, V. (2004). The reflective cultural portfolio: Identifying public cultural scripts in the private voices of white student teachers. Journal of Teacher Education, 55(2), 116-127.

McCaffery, J., \& Tuafuti, P., in association with Maihi, S., Elia, L., Ioapo, N., \& Aukuso, S. (2003). Samoan children’s bilingual language and literacy development. In R. Barnard \& T. Glynn (Eds.). Bilingual children's language and literacy development (pp. 80-107). Clevedon, UK: Multilingual Matters Ltd.

McNaughton, S. (2002). Meeting of minds. Wellington, NZ: Learning Media.

McNaughton, S., Phillips, G.E., \& MacDonald, S. (2003). Profiling teaching and learning needs in beginning literacy instruction: The case of children in "low decile" schools in New Zealand. Journal of Literacy Research, 35(2), 703-730. 
Multicultural Affairs Queensland - Department of the Premier and Cabinet. (1999).

Queensland Government Position Statement on Immigration. Retrieved 10 October, 2005, from http://www.premiers.qld.gov.au/library/pdf/default/immigstat.pdf.

Nash, R. (2000). Educational inequality: The special case of Pacific students. Social Policy Journal of New Zealand, 15, 69-85.

Nieto, S. (2004). Affirming Diversity: The Sociopolitical Context of Multicultural Education (4th ed.). Boston, MA: Allyn and Bacon.

Queensland College of Teachers. (2007). Professional Standards for Queensland Teachers: The State of Queensland.

Queensland Government. (2003). Demographic profile of Logan City. Brisbane: Department of Local Government and Planning, Queensland Government.

Singh, P. (2001). Speaking about Cultural Difference and School Disadvantage. An Interview study of ‘Samoan’ Paraprofessionals in Designated Disadvantaged Secondary Schools in Australia. British Journal of Sociology of Education, 22(3), 317-337.

Sleeter, C., \& Grant, C. (2003). Making Choices for Multicultural Education: Five Approaches to Race, Class, and Gender (4th ed.). New York: Wiley.

Thomas, S., \& Cooper, M. (in press). Global Imaginings, Imagining the teacher. In J. Zajda (Ed.), International Handbook on Globalization, Education and Policy Research Global Pedagogies and Policies: Springer.

Yeung, A. S. W. (2006). Teachers' Conceptions of Borderless - A Cross-Cultural Study on Multicultural Sensitivity of the Chinese Teachers. Educational Research for Policy and Practice, 5, 33-53. 


\section{Appendix}

Please provide some information about yourself and your class/classes by placing (x) in the relevant box.

\begin{tabular}{|c|c|c|c|c|}
\hline I have been teaching for: & $\square 1-3$ years & $\square$ 4-8 years & $\square>8$ years & \\
\hline I currently teach: & $\square$ Years P-3 & $\square$ Years 4-5 & $\square$ Years 6-7 & $\square$ Years 8-12 \\
\hline I am a graduate from Griff & & $\square$ Yes & $\square$ No & \\
\hline
\end{tabular}

I am: $\quad \square$ Monolingual $\quad \square$ Bilingual $\square$ Multilingual

If bilingual or multilingual, languages spoken are:

Percentage of students in your class with a non-English speaking background (NESB):

$\square 0 \%-10 \% \quad \square 10 \%-20 \% \quad \square 20 \%-30 \% \quad \square>30 \%$

Cultural groups represented in your class/classes: $\square$ ATSIC $\square$ African $\square$ ATSIC $\square$ Asian $\square$ Pacific Islander

$\square$ Middle Eastern $\square$ European (Excluding United Kingdom)

My pre-service training prepared me to teach NESB students $\quad \square$ Yes $\quad \square$ No

I have had in-service training opportunities to develop as a teacher of NESB students $\quad \square$ Yes $\quad \square$ No

I have had post-grad training opportunities to develop as a teacher of NESB students $\quad \square$ Yes $\quad \square$ No

Each of the following statements relates to Pacific Islander students. Please read the statement carefully then circle one of the numbers on the right. Where:

1= Strongly Disagree $\quad 2=$ Disagree $\quad 3=$ Undecided $\quad 4=$ Agree $\quad 5=$ Strongly Agree

I am able to determine the English language proficiency of Pacific Islander students as:

- Speakers and listeners.

$\begin{array}{lllll}1 & 2 & 3 & 4 & 5\end{array}$

- Readers and writers.

$\begin{array}{lllll}1 & 2 & 3 & 4 & 5\end{array}$

I feel confident responding to the English literacy needs of Pacific Islander students

$\begin{array}{lllll}1 & 2 & 3 & 4 & 5\end{array}$

I am happy with the academic achievement of my Pacific Islander students

$\begin{array}{lllll}1 & 2 & 3 & 4 & 5\end{array}$

I am aware of the traditional communication patterns, (e.g. turn-taking, non verbal cues,) of

Pacific Islander groups.

$\begin{array}{lllll}1 & 2 & 3 & 4 & 5\end{array}$

I know how a Pacific Islander language is different from or similar to English

$\begin{array}{lllll}1 & 2 & 3 & 4 & 5\end{array}$

I am familiar with the social and cultural experiences of Pacific Island students

$\begin{array}{lllll}1 & 2 & 3 & 4 & 5\end{array}$

Please respond in writing to these 2 questions:

What issues are of concern to you regarding the educational achievement of Pacific Islander students?

What strategies work well with Pacific Island students? 


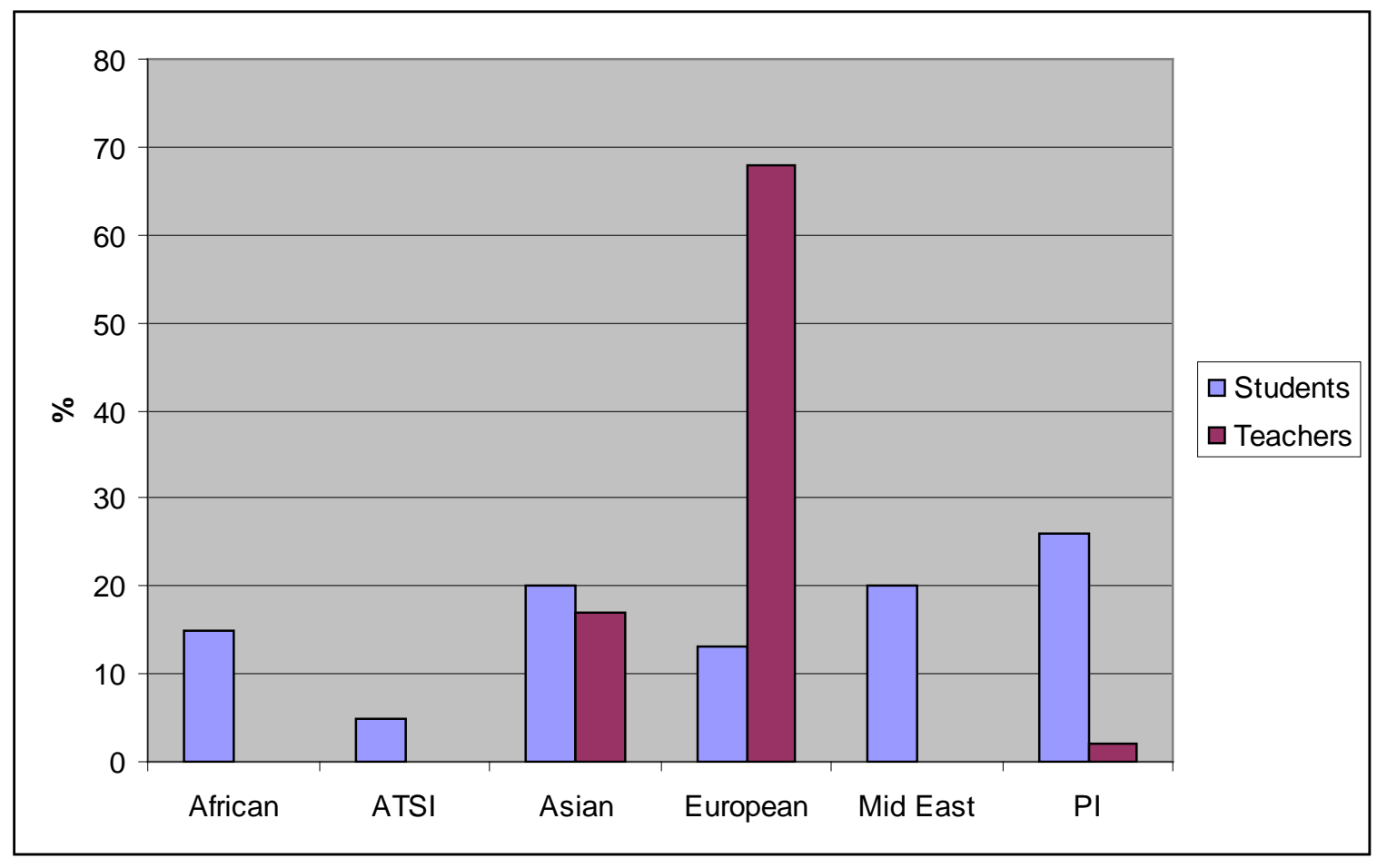

Figure 1. Linguistic backgrounds reported by NESB students and by teachers. 


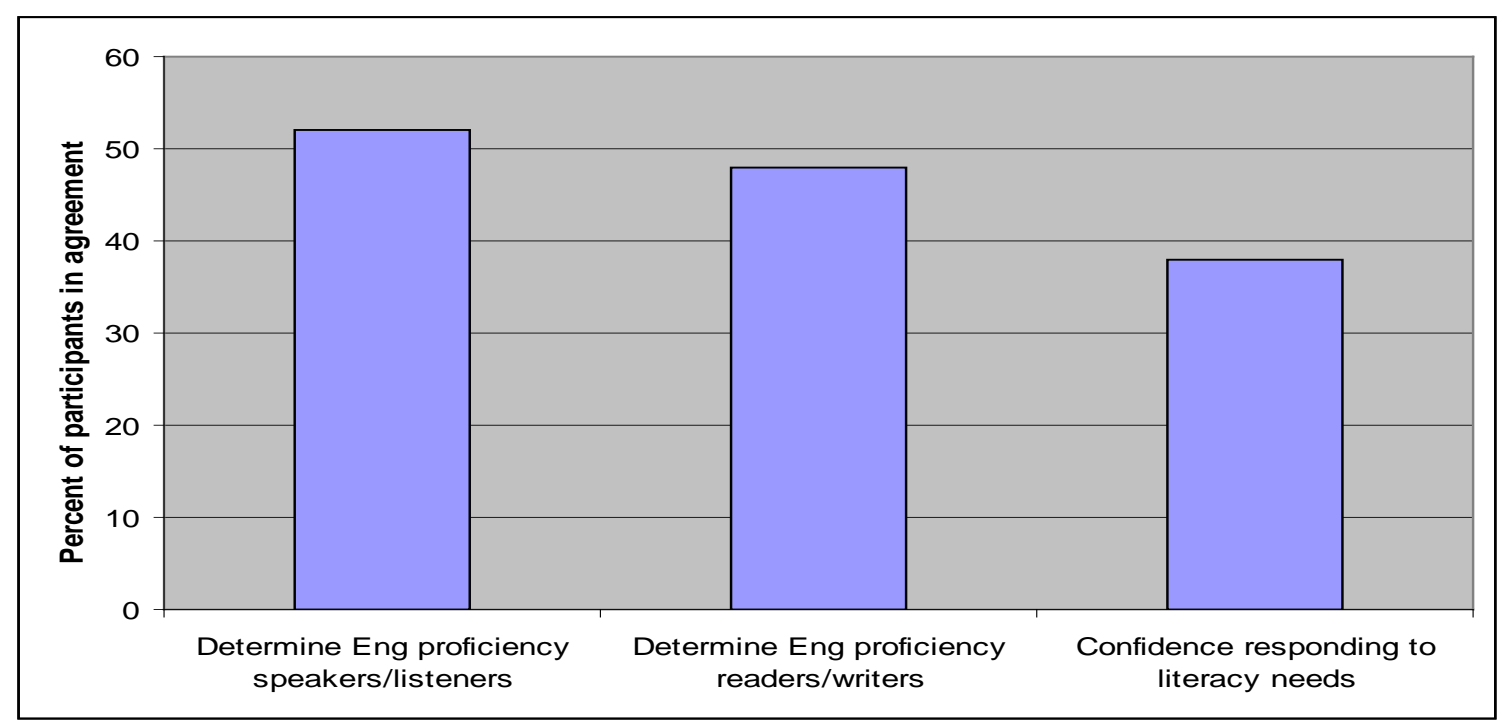

Figure 2. Responses to Likert-scale items measuring teachers' support for PI students’ literacy development 


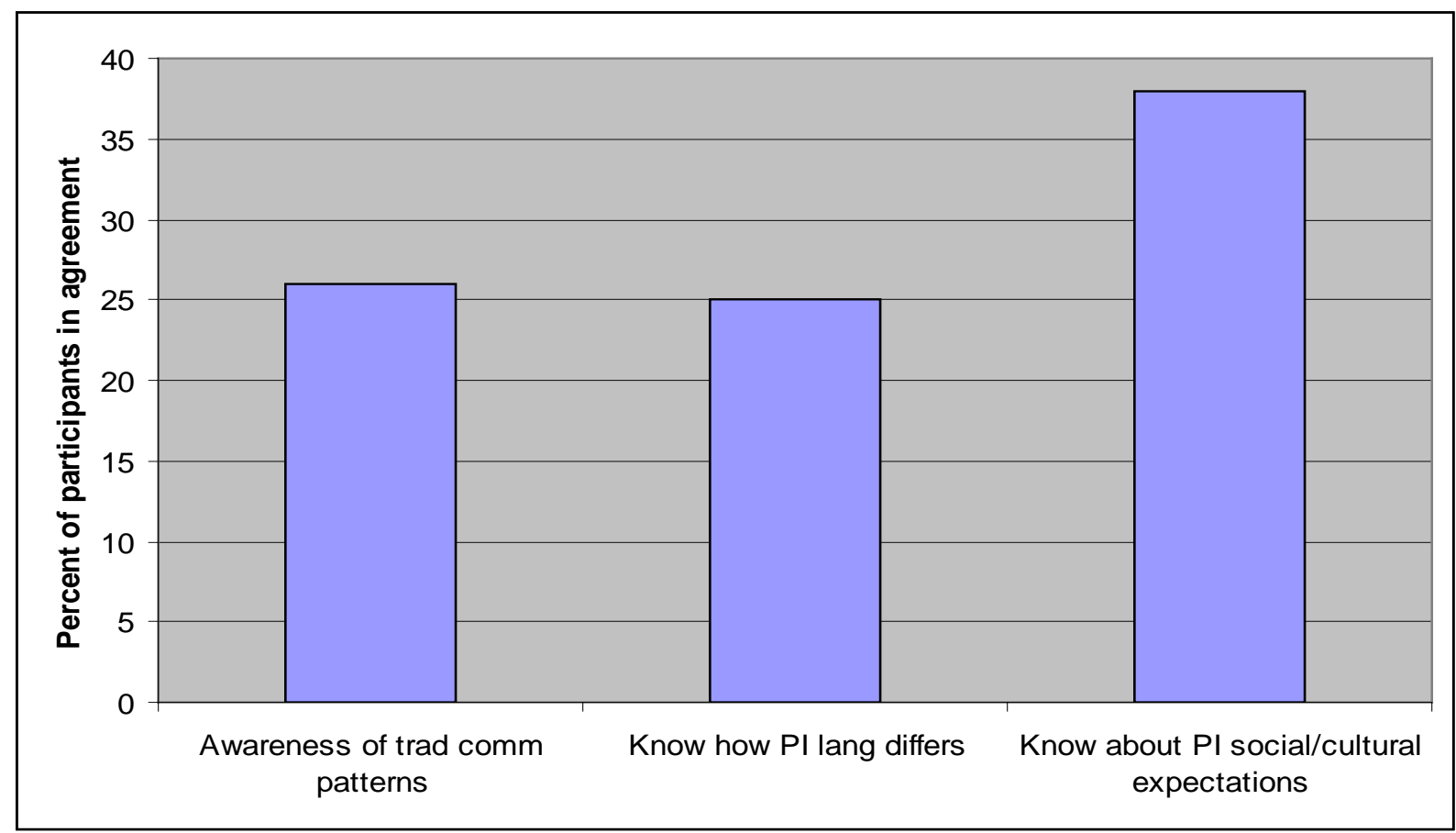

Figure 3. Responses to Likert-scale items measuring teachers' intercultural understanding 


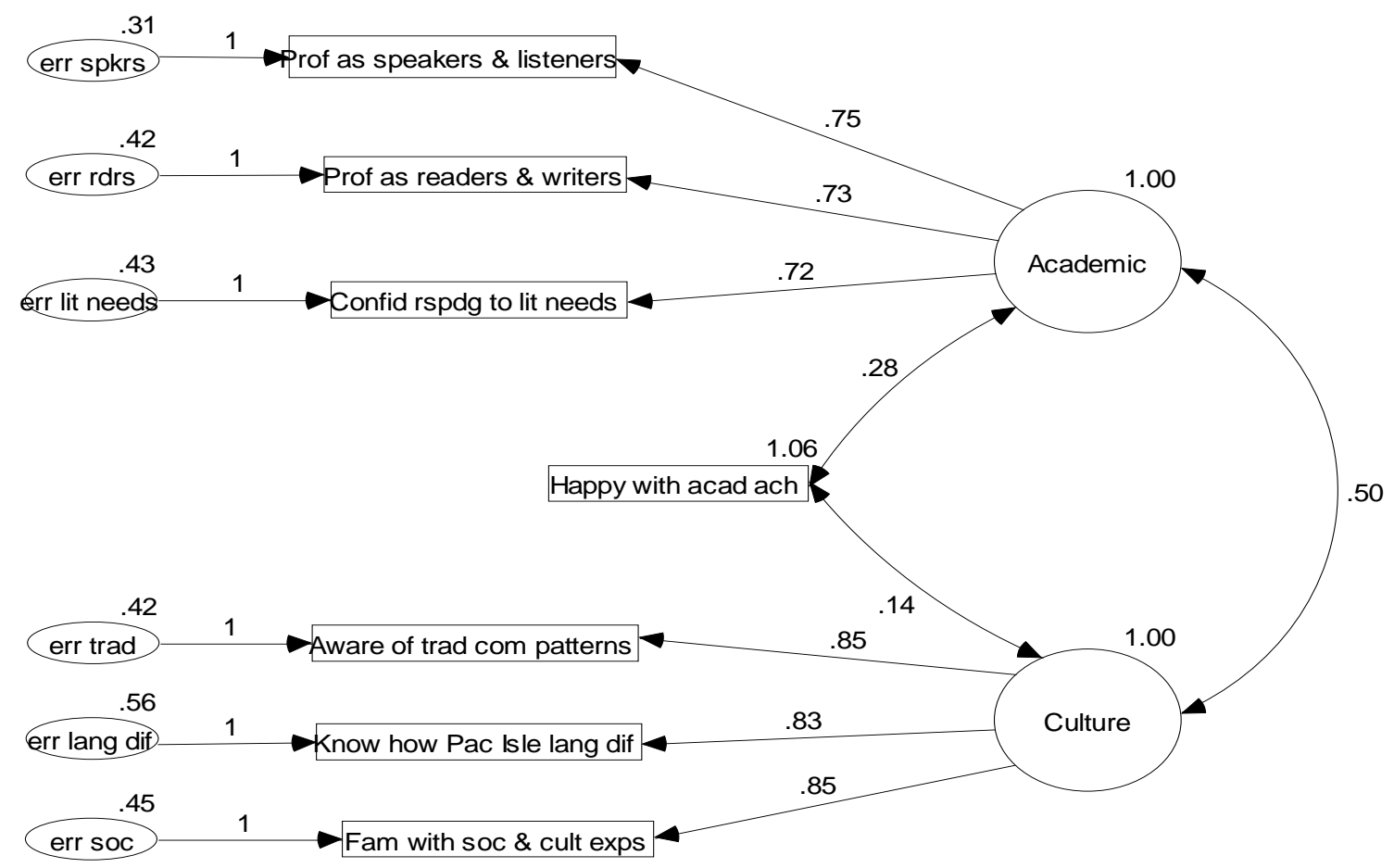

Figure 4. Confirmatory factor analytic model of associations between items and latent variables (standardised regression weights) 


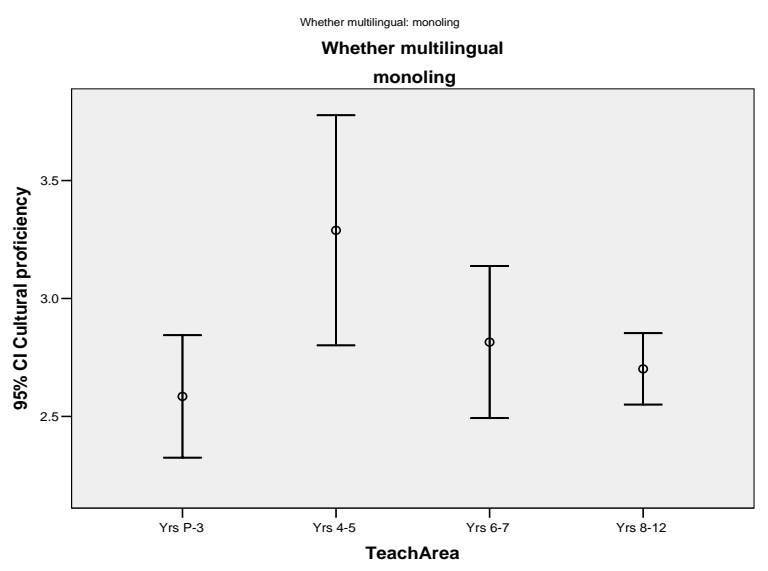

Figure 5. Interaction between teaching area and monolingual status 


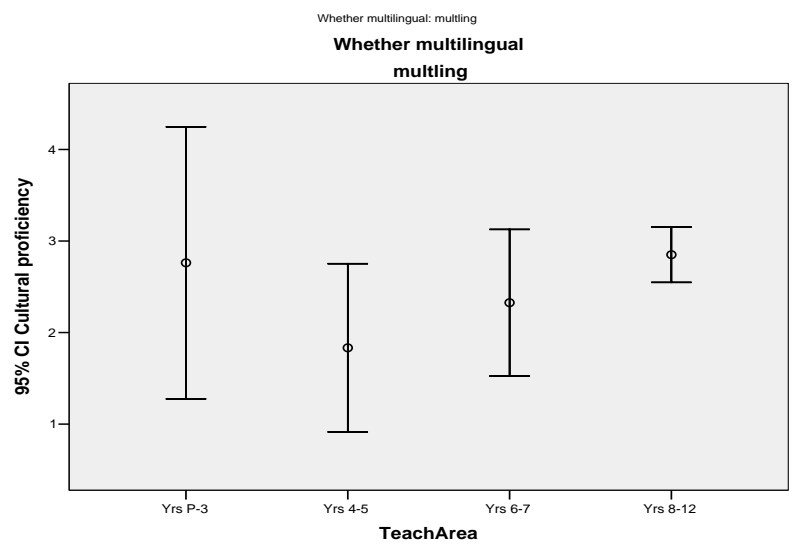

Figure 6. Interaction between teaching area and multilingual status 